\title{
Impacts of the Allocation Mechanism Under the Third Phase of the European Emission Trading Scheme
}

\author{
Wolfgang Eichhammer ${ }^{1,2, *(\mathbb{D})}$, Nele Friedrichsen ${ }^{3}$, Sean Healy ${ }^{4}$ and Katja Schumacher ${ }^{4}$ \\ 1 Fraunhofer Institute for Systems and Innovation Research ISI, 76139 Karlsruhe, Germany \\ 2 Copernicus Institute of Sustainable Development, Utrecht University, 3584 CB Utrecht, The Netherlands \\ 3 Fraunhofer Institute for Systems and Innovation Research ISI, Now with: DB Energie GmbH, \\ 60326 Frankfurt a.M., Germany; nele.friedrichsen@deutschebahn.com \\ 4 Öko-Institut e.V.-Institute for Applied Ecology, 10179 Berlin, Germany; s.healy@oeko.de (S.H.); \\ k.schumacher@oeko.de (K.S.) \\ * Correspondence: wolfgang.eichhammer@isi.fraunhofer.de or w.a.eichhammer@uu.nl; Tel.: +49-721-6809-158
}

Received: 6 May 2018; Accepted: 3 June 2018; Published: 4 June 2018

\begin{abstract}
This paper focuses on the following two key research questions in the context of the change in allocation rules in the move from Phase I/II (2005-2012) to Phase III (2013-2020) of the European Emission Trading Scheme (EU ETS): First, how do allocations compare with actual installation-verified emissions in Phase III? For that purpose we analyse changes in sector-country allocations and verified emissions between Phase II and Phase III. The analysis is based on a selection of 2150 installations present in all phases of the EU ETS, taken from the European Union Transaction Log (EUTL) The results show that over-allocation has been considerably reduced in Phase III. Overall, allocation for the selected sectors decreased by $20 \%$ in 2013 compared to 2008 but varying across installations. Second, we investigate, whether the introduction of benchmarks in Phase III may have triggered carbon-reducing measures for industrial processes. For that purpose, we analyse for four product groups (cement clinker, pig iron, ammonia and nitric acid) the specific emissions (per tonne of product). Care was taken to define a data set with a similar delimitation of emission and production data. The findings were cross-checked through selected expert interviews. Our findings indicate that there is no evidence so far for improving specific emissions, though the strong improvement for nitric acid, as well as some improvement linked to ammonia occurring before the start of Phase III may have been supported by the introduction of Phase III.
\end{abstract}

Keywords: emission trading; benchmarking; specific emissions; allocation; verified emissions

\section{Introduction}

The European Emission Trading Scheme (EU ETS) is a core part of EU climate change policy and every year installations covered by the system must acquire and surrender allowances equal to their verified emissions. It operates in $28 \mathrm{EU}$ countries and three EEA-EFTA states (European Economic Area-European Free Trade Association: Iceland, Liechtenstein and Norway). It covers around 45\% of the EU's greenhouse gas emissions and includes over 11,000 heavy energy-using installations in power generation and manufacturing industries.

The EU ETS established a carbon market in which emissions allowances have a value. There are three main approaches to allocate allowances to incumbents: (1) allocation according to historic emissions (minus required savings) or grandfathering; (2) allocation according to benchmarks (e.g., determined on the basis of the $10 \%$ best or Best Available Technology); (3) auctioning.

To mitigate the risk that the cost associated with these allowances could competitively disadvantage EU industry relative to those that are not subject to the same carbon pricing, many of 
the allowances are issued to them for free. For the 1st and 2nd trading period (Phase I of the EU ETS: 2005-2007; Phase II: 2008-2012), free allocation was based on national allocation plans (NAPs) and grandfathering. This decentralized approach was criticized because it creates substantial differences in allocations across countries that could cause competitive distortions. The decentralized approach also adds complexity to the scheme and thereby increases transaction cost [1]. Further criticism related to large allocation surpluses and insufficient incentives to reduce emissions [2].

Major revisions to strengthen the EU ETS were therefore undertaken for Phase III (2013-2020), especially with respect to allowance allocation [3]. The following changes are especially important:

- The move to a single Union-wide cap instead of national caps standardised the approach to improve the harmonisation of ambition between Member States and therefore the level of allocation to their industries.

- Auctioning has become the default method for allowance distribution, reducing the number of allowances that are provided for free. Theoretically auctioning of allowances is preferred since it avoids rent seeking behavior in decision about distribution of allocations. Further, auctioning is consistent with the polluter pays principle which likely increases the perceived fairness of the auction's outcome [2]. However, in practice auctioning shares so far remained low except in the electricity sector because of concerns over carbon leakage. Free allocation is considered as second best to protect leakage exposed industries [4].

- Harmonised rules for free allocation based on benchmarks (for products and fall-back approaches for heat and fuels) standardised the approach for installations within each sector or subsector. The product benchmarks have been defined based on the $10 \%$ best performing installations. The benchmark-based allocation rewards efficient installations that will receive a relatively complete endowment with certificates to cover their emissions while installations with a relatively poor emission performance will face a deficit in allocations compared to emissions.

These revisions are likely to have had an impact on industries covered by the system. Relative to the previous allocation method (based mainly on historic emissions-based grandfathering under national caps), the new approach affects the distribution of value of free allowances between installations within and across sectors. Good practice in low emission production is in principle rewarded in preference to higher carbon intensity operations because the allocation is independent of an installation's actual emissions (at least as long as over-allocation is avoided). Installations operating nearer to the benchmark will receive a greater proportion of their allowances for free.

As a key instrument to reduce greenhouse gas (GHG) emissions the EU ETS has been evaluated both from an ex-ante and an ex-post perspective, with the first dominating the early years of the EU ETS, naturally. Ex-post analysis has been carried out on various aspects such as:

- Effectiveness of the EU ETS in reducing GHG emissions which is the primary objective of an emission trading scheme [5-9];

- Cost efficiency in reducing GHG emissions [10];

- Carbon leakage effects and impacts on economic performance, competitiveness [8,11];

- Impacts on employment, investment and productivity [12];

- Innovation impacts $[7,13,14]$;

- $\quad$ Trading aspects [15];

- Interaction with other policy instruments [16,17];

- Transaction cost $[8,18]$

- Methodological aspects with respect to evaluating the EU ETS $[7,9,10]$;

With respect to the effectiveness of the ETS to reduce GHG emissions, the difficulty resides in the need to separate impacts of other factors than the EU ETS (e.g., the economic crisis from EU ETS, specific energy policies such as for renewables and energy efficiency, structural changes due to globalisation) from the impacts of the policy itself. A number of studies conclude on a substantial 
reduction of 100-200 million tonnes of $\mathrm{CO}_{2}$-equivalents [7]. However, the distinction of what is due to the before mentioned effects and the EU ETS is difficult to make, especially in a case of low carbon prices and over-allocation as was the period for most of the lifetime of the EU ETS so far. Further, these studies do not have a specific look to the manufacturing sector.

Particularly interesting is the question whether the EU ETS has not only led to a reduction of activity levels but also to the reduction of specific emissions [8]. While both effects contribute to the effectiveness of emission trading (the first, by putting pressure on carbon-intensive activities, the second, by triggering process innovations), it is the second effect, which is most desirable from a policy maker perspective, as it may contribute to enhancing competitiveness and innovation in the economy. So far, there was little investigation from a bottom-up perspective (i.e., at the level of individual industrial production processes) on changes of specific emissions. The present paper contributes to closing this gap. Some research has been carried out on individual industrial branches in the past, but mainly with a focus of carbon leakage [11].

This paper focuses on the following two key research questions:

- How do allocations compare with actual installation verified emissions? The purpose of this analysis is to determine at detailed sector and country level, the evolution from Phase I/II (which have been characterised by large over-allocation) to Phase III.

- How do actual verified emissions of installations compare with benchmark values? For that purpose, we focus in an exemplary manner on four important products: cement clinker, pig iron production, ammonia production and the production of nitric acid (as an important emitter of nitrous oxide $\mathrm{N}_{2} \mathrm{O}$, a powerful greenhouse gas).

To examine the first research question we investigated the ratios "Allocation 2008/Verified Emissions 2008" and "allocation 2013/average allocation Phase II". The first ratio measures whether there was over-allocation of free allowances at the beginning of Phase II (starting in 2008), while the second measures in how far this has been corrected in the allocation of Phase III (starting in 2013).

The second research question, the analysis of benchmark values relative to actual performance involves the construction of sector specific emission intensities (emissions divided by production volume), using mostly publically available production data. The specific emission intensity values are compared with the benchmarks [3] for the four case studies. The hypothesis to be verified was that the changes in allocation rules for Phase III may have influenced specific emissions, bearing in mind that emissions in Phase III are only available for 2013 to 2017 so far, though Phase III changes may have had impacts before its start (see the discussion on nitric acid in the results section). We therefore also include the time period from 2005-2012 in the analysis. The research comprised two principal elements. First, the available data and information were analysed to identify preliminary findings and indications. Second, interviews were carried out with selected sector and country representatives to gather further insights and information to inform the analysis.

\section{Methodology and Data}

\subsection{Methodology for the Comparison of Allocation with Actual Emissions}

The analysis for the first research question is based on a dataset compiled by the authors. Primary source are data on verified emissions and free allocation from the EU Transaction Log (EUTL) [19] (date of extraction: 1 April 2017) as published by the European Commission in the verified emissions table. The file includes verified emissions and free allocation for 2008-2016 as well as free allocation for 2017-2020. This file was linked to the sector classification according to NACE Rev 2-Statistical classification of economic activities [20], based on the classification published by the European Commission during the preparation of the second carbon leakage list for 2015-2019 [21]. The analysis concentrated on installations marked as open and for which a NACE classification was available. Installations with activity code 10 (aviation) were omitted. For a meaningful comparison of 
installations in the 3rd trading period vis-à-vis the 2nd trading period it was necessary to establish a dataset including only installations for which allocations and verified emissions in both 2nd and 3rd trading period are available. Installations with missing data were excluded. The dataset was further limited to concentrate on the emission intensive industries.

Tables 1 and 2 provide an overview of the selected sample. Note, that for the countries Iceland (IS), Malta (MT) and Croatia (HR) no installations remain in the data set. The comparison is based on several indicators:

- In a first step, the ratio of allocation to verified emissions was established for 2008, as a year of the second trading period that was probably not yet affected by the economic downturn, as well as for 2013 as the starting year for the 3rd trading period. The year 2013 was used to focus the analysis on effects from the introduction of benchmark-based allocation. Otherwise, the linear reduction of allocation to installations producing non-carbon leakage exposed products would also be captured. The two ratios indicate whether there had been surpluses in allocation.

- Second, the ratio of allocation 2008 to verified emissions 2008 was calculated as an indicator for potential over-allocation of free allowances at the start of the 2nd trading period.

- Third, the ratio of allocation 2013 to average allocation 2nd trading period was calculated. Substracting one from this ratio gives the percentage change in allocation.

Comparing the ratio of allocation to verified emission 2008 with the allocation change in 2013 gives an indication of whether the changes contributed to correcting allocation surpluses that existed in the 2nd trading period. 
Table 1. Sample size and distribution of the average allocation change in 2013 compared to the average of the 2nd Trading Period (TP) by NACE Code.

\begin{tabular}{|c|c|c|c|c|c|}
\hline NACE Rev. 2 & Subsector Name & $\begin{array}{c}\text { Number of } \\
\text { Installations in Sample }\end{array}$ & $\begin{array}{l}\text { Average Allocation } \\
\text { 2008-2012 ( } \mathrm{Mt} \mathrm{CO}_{2} \text { eq) }\end{array}$ & $\begin{array}{l}\text { Allocation } 2013 \\
\left(\mathrm{Mt} \mathrm{CO}_{2} \mathrm{eq}\right)\end{array}$ & $\begin{array}{c}\text { Allocation Change } 2013 \\
\text { Compared to Average 2nd TP }\end{array}$ \\
\hline 17.12 & paper and paperboard & 493 & 30.14 & 24.24 & $-20 \%$ \\
\hline 19.1 & coke oven products & 17 & 4.93 & 4.11 & $-17 \%$ \\
\hline 19.2 & refined petroleum products & 112 & 133.49 & 102.90 & $-23 \%$ \\
\hline 20.11 & industrial gases & 5 & 1.26 & 1.40 & $11 \%$ \\
\hline 20.14 & other organic basic chemical & 147 & 55.23 & 35.92 & $-35 \%$ \\
\hline 20.15 & fertilisers and nitrogen compounds & 46 & 8.17 & 13.00 & $59 \%$ \\
\hline 20.16 & plastics in primary forms & 47 & 3.43 & 2.84 & $-17 \%$ \\
\hline 23.11 & flat glass & 42 & 6.04 & 4.20 & $-31 \%$ \\
\hline 23.13 & hollow glass & 167 & 10.98 & 7.86 & $-28 \%$ \\
\hline 23.14 & glass fibres & 44 & 1.44 & 0.89 & $-38 \%$ \\
\hline 23.19 & other glass, incl. technical glassware & 35 & 0.79 & 0.62 & $-22 \%$ \\
\hline 23.32 & bricks, tiles, construction products, in baked clay & 360 & 8.04 & 5.12 & $-36 \%$ \\
\hline 23.51 & cement & 198 & 149.25 & 122.29 & $-18 \%$ \\
\hline 23.52 & lime and plaster & 184 & 32.11 & 23.94 & $-25 \%$ \\
\hline 23.62 & plaster products for construction purposes & 7 & 0.20 & 0.17 & $-15 \%$ \\
\hline 24.1 & basic iron and steel and of ferro-alloys & 226 & 184.88 & 144.00 & $-22 \%$ \\
\hline 24.2 & tubes, pipes, hollow profiles and related fittings, of steel & 11 & 1.01 & 0.64 & $-36 \%$ \\
\hline \multirow[t]{2}{*}{24.51} & casting of iron & 9 & 1.54 & 0.89 & $-43 \%$ \\
\hline & Total & 2150 & 632.94 & 495.01 & $-22 \%$ \\
\hline
\end{tabular}


Table 2. Sample size and distribution of the average allocation change in 2013 compared to the average of the 2nd Trading Period (TP) by country (Registry Code).

\begin{tabular}{|c|c|c|c|c|}
\hline $\begin{array}{c}\text { Registry } \\
\text { Code/Country }\end{array}$ & $\begin{array}{c}\text { Number of } \\
\text { Installations in Sample }\end{array}$ & $\begin{array}{c}\text { Average Allocation } \\
\text { 2008-2012 }\left(\mathrm{Mt} \mathrm{CO}_{2} \mathrm{eq}\right)\end{array}$ & $\begin{array}{l}\text { Allocation } 2013 \\
\left(\mathrm{Mt} \mathrm{CO}_{2} \text { eq) }\right.\end{array}$ & $\begin{array}{c}\text { Allocation Change } 2013 \\
\text { Compared to Average 2nd TP }\end{array}$ \\
\hline AT-Austria & 70 & 14.72 & 16.87 & $15 \%$ \\
\hline BE-Belgium & 91 & 21.01 & 16.67 & $-21 \%$ \\
\hline BG-Bulgaria & 19 & 4.89 & 3.65 & $-25 \%$ \\
\hline CY-Cyprus & 1 & 1.34 & 0.84 & $-37 \%$ \\
\hline CZ-Czech Republic & 87 & 20.74 & 16.78 & $-19 \%$ \\
\hline DE-Germany & 435 & 107.70 & 83.68 & $-22 \%$ \\
\hline DK-Denmark & 26 & 3.87 & 3.33 & $-14 \%$ \\
\hline EE-Estonia & 7 & 1.15 & 1.06 & $-8 \%$ \\
\hline ES-Spain & 221 & 64.56 & 47.11 & $-27 \%$ \\
\hline FI-Finland & 40 & 14.58 & 12.50 & $-14 \%$ \\
\hline FR-France & 233 & 68.47 & 52.38 & $-23 \%$ \\
\hline GB-Great Britain & 118 & 58.42 & 39.33 & $-33 \%$ \\
\hline GR-Greece & 43 & 15.23 & 11.94 & $-22 \%$ \\
\hline HU-Hungary & 33 & 6.03 & 7.01 & $16 \%$ \\
\hline IE-Ireland & 10 & 4.74 & 3.32 & $-30 \%$ \\
\hline IT-Italy & 283 & 70.50 & 63.39 & $-10 \%$ \\
\hline LT-Latvia & 11 & 3.72 & 4.33 & $16 \%$ \\
\hline LU-Luxembourg & 5 & 1.20 & 1.09 & $-10 \%$ \\
\hline LV-Latvia & 6 & 0.53 & 0.19 & $-64 \%$ \\
\hline NL-Netherlands & 75 & 36.27 & 25.84 & $-29 \%$ \\
\hline NO-Norway & 27 & 5.80 & 5.63 & $-3 \%$ \\
\hline PL-Poland & 87 & 29.26 & 24.44 & $-16 \%$ \\
\hline PT-Portugal & 55 & 12.78 & 9.65 & $-24 \%$ \\
\hline RO-Romania & 53 & 28.28 & 14.81 & $-48 \%$ \\
\hline SE-Sweden & 71 & 17.71 & 15.66 & $-12 \%$ \\
\hline SI-Slovenia & 18 & 1.50 & 1.29 & $-14 \%$ \\
\hline SK-Slovak Republic & 25 & 17.94 & 12.21 & $-32 \%$ \\
\hline Total & 2150 & 632.94 & 495.01 & $-22 \%$ \\
\hline
\end{tabular}

\subsection{Methodology for Measuring Impacts of Benchmarks for Allocation on Verified Emissions}

The approach taken for the comparison of benchmark values with actual emissions was to divide emissions for the products by an appropriate activity level and compare the obtained specific emissions with the benchmarks for the four products cement clinker, pig iron, ammonia and nitric acid.

Establishing specific emissions for product groups is not straightforward, given that the delimitation of the production processes has a strong impact on the specific consumption. This was the main reason for developing sub-installations for the benchmarks in Phase III [3], i.e., well defined parts of installations which are largely comparable. Analysis at a sectoral statistical level (see for example [22]) is facing difficulties such as identification of ETS installations, emission/production delimitation issues etc.

The approach taken focused on product benchmarks and was therefore the most detailed approach possible, given the data availability and without additional data collection. The approach is summarised as follows, and was applied to cement clinker and pig iron and ammonia. The data for nitric acid have been obtained directly from the sector association Fertilizers Europe [23].

- First, a subset of installation data concerning emissions is selected from the public European Transaction Log EUTL [19] for the sector which covers the whole period from 2005 up to the last available year in the register at the time of the analysis (2017, i.e., the fifth year in Phase III). Limitations in the availability of production data limited this, however, de facto to 2016, except for pig iron. Data for plants which have been closed or opened in the period of consideration were excluded from the dataset. For nitric acid and ammonia, this approach was not possible, as these products entered the ETS only in 2013; hence, in difference to cement clinker and pig iron, the EUTL does not contain data from 2005 to 2012 and analysis before Phase III had to be taken interviews with the association Fertilizers Europe [23].

- Second, the activity data for the different products and individual installations available for the period 2005-2010 were taken from a non-public database collected for the allocation for Phase III of the ETS, the so-called National Implementation Measures (NIMS) data. Production was available in an aggregate manner for each product considered in this paper but with the same underlying disaggregation of installations as for the emissions. Below we will discuss the importance of 
having the same installations for emissions and activities. Mostly this information is for the period 2005-2008. The activity measure is the same activity measure used for the benchmarks [3], i.e., usually physical production of the product group.

- As installations can be fairly heterogeneous entities, the installations had to be decomposed into sub-installations, where each sub-installation reflected as close as possible the definition of the processes underlying the benchmark definition of interest. The NIMS data mentioned above, further provide information on the share of an installation's allocation at sub-installation level for product and fallback benchmarks. This was also based on average shares for the period 2005-2010. The assumption is made that the emissions shares for the product benchmarks for different sub-installations in overall emissions of the installation remain the same over time as the split indicated for the period 2005-2010. For cement clinker these average shares are $98 \%$ and for pig iron 79\%. The emissions of the installations are then corrected with these factors to extract the emissions relevant for the product benchmark under consideration. This was only possible for cement clinker and pig iron, as ammonia and nitric acid were not part of the EUTL before 2013 (or only with production parts such as steam generators).

- The activities are then extended to 2016/2017-the last year for which data on emissions for installations or production data are available - by use of an index. This avoids the problem that the ratio of emissions and activity data is impacted by a different delimitation of numerator and denominator, at least to a large degree as the indices are less influenced than the absolute levels.

- Such indices can be derived in principle from the following data sources:

Prodcom statistics (based on total production volume) [24]

- Activity statistics from associations

We discuss in the following the quality of these sources. In particular, Prodcom data may have problems with respect to the completeness of data.

- The emission data corrected for the shares of the product benchmarks are then divided by the extrapolated activity data and compared with the benchmarks to calculate which emission reduction may have occurred. If an installation produces several products the share of each product would be considered separately with this approach to allow a comparison of emissions compared to the benchmark. The emission parts allocated to the fall back sub-installations are excluded from the consideration. However, for cement clinker and pig iron the share of the main sub-installation considered here is very large compared to other product groups.

\section{Results}

\subsection{Comparison of Allocation with Actual Emissions}

The new allocation rules had a substantial effect on the allocation towards installations in the sample. Overall, allocation for the selected sectors decreased by 20\% in 2013 compared to 2008 . The allocation change varies at sector level and by country.

\subsubsection{Allocation Changes at Sectoral Level}

At the aggregate level, i.e., comparing the sum of allocations 2008-2013 per sector, allocation decreased in all but two sectors (Table 3 and Figure 1). The sectors in which allocations decreased most are NACE 24.51 (casting of iron), with a reduction of $-43 \%, 23.14$ with $-38 \%, 24.2$ with $-36 \%$, 20.14 with $-34 \%$ and 23.32 with $-33 \%$. An increase in allocation 2013 compared to 2008 at sector level can be observed for 20.15 (fertilisers and nitrogen compounds) $(+88 \%)$ and $20.11(+11 \%)$. On average the changed allocation contributed to the reduction of a surplus in allocations compared to verified emissions. While the ratio of allocation to verified emissions was larger than 1 in all but three sectors $(19.2,23.62$ and 24.51) in 2008 (Figure 1), the ratio was smaller than one in all but six sectors in 2013. For 
three sectors (23.51 cement, 23.62 plaster products for construction purposes and 24.51 casting of iron), the allocation to verified emissions ratio is larger in 2013 than in 2008. This occurred despite strongly reduced allocation since verified emissions decreased even more. For the latter two, this might be influenced by the very small sample (seven of nine installations, respectively), but also in the cement sector, there seems to be a strong impact from outliers. The median change is a reduction of $-9 \%$. In general, emission reductions do not necessarily indicate efficiency increases but might be a result of production decreases.

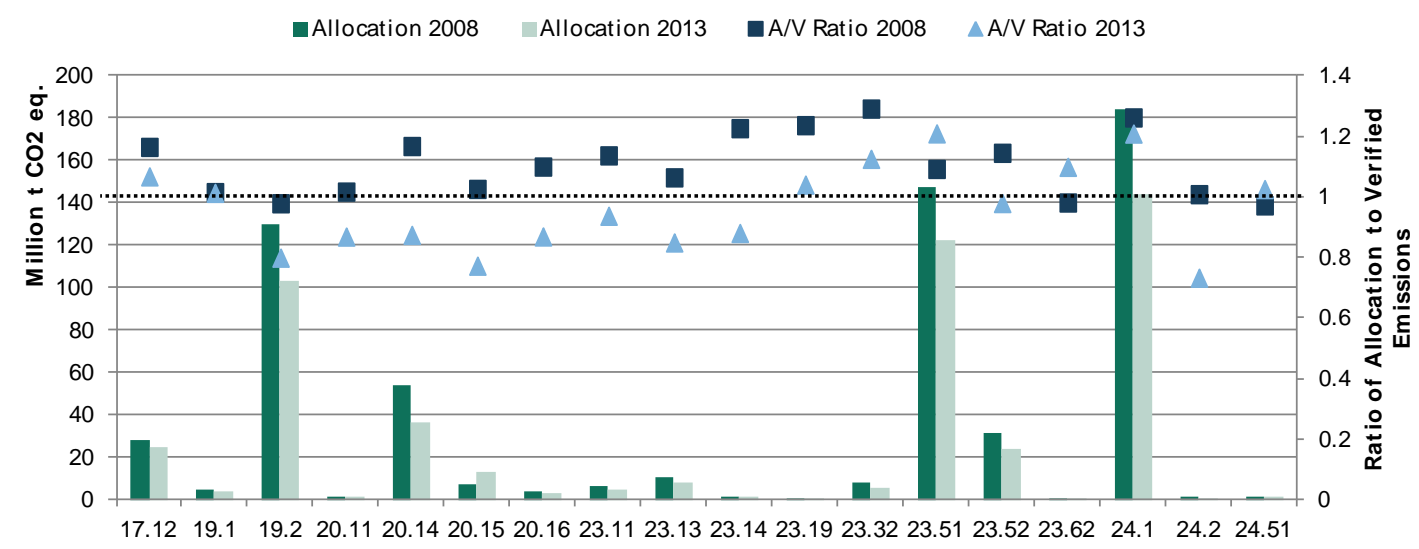

Figure 1. Allocation and Ratio of Allocation to Verified Emissions (A/V) in 2008/2013 by NACE Code. Note: For the list of NACE codes, see Table 3.

Table 3. Sample size and distribution of the average allocation change in 2013 compared to the average of the 2nd Trading Period (TP) by NACE Code.

\begin{tabular}{|c|c|c|c|c|c|c|c|}
\hline \multirow[t]{2}{*}{$\begin{array}{l}\text { NACE } \\
\text { Rev. } 2 \\
\end{array}$} & & \multirow[t]{2}{*}{$\begin{array}{l}\text { Number of } \\
\text { Installations }\end{array}$} & \multicolumn{5}{|c|}{ Quantiles } \\
\hline & & & x.0\% & $x .25 \%$ & $x .50 \%$ & $x .75 \%$ & $\mathrm{x} .100 \%$ \\
\hline 17.12 & paper and paperboard & 493 & $-98 \%$ & $-48 \%$ & $-22 \%$ & $5 \%$ & $175,330 \%$ \\
\hline 19.1 & coke oven products & 17 & $-40 \%$ & $-32 \%$ & $-8 \%$ & $34 \%$ & $98 \%$ \\
\hline 19.2 & refined petroleum products & 112 & $-96 \%$ & $-36 \%$ & $-20 \%$ & $-6 \%$ & $334 \%$ \\
\hline 20.11 & industrial gases & 5 & $-83 \%$ & $-45 \%$ & $-2 \%$ & $115 \%$ & $129 \%$ \\
\hline 20.14 & other organic basic chemical & 147 & $-98 \%$ & $-42 \%$ & $-24 \%$ & $5 \%$ & $2976 \%$ \\
\hline 20.15 & fertilisers/nitrogen compounds & 46 & $-93 \%$ & $-46 \%$ & $-9 \%$ & $256 \%$ & $7628 \%$ \\
\hline 20.16 & plastics in primary forms & 47 & $-86 \%$ & $-55 \%$ & $-18 \%$ & $37 \%$ & $1281 \%$ \\
\hline 23.11 & flat glass & 42 & $-76 \%$ & $-33 \%$ & $-28 \%$ & $-22 \%$ & $-2 \%$ \\
\hline 23.13 & hollow glass & 167 & $-84 \%$ & $-35 \%$ & $-26 \%$ & $-13 \%$ & $115 \%$ \\
\hline 23.14 & glass fibres & 44 & $-84 \%$ & $-55 \%$ & $-40 \%$ & $-30 \%$ & $65 \%$ \\
\hline 23.19 & other glass, including technical glassware & 35 & $-66 \%$ & $-21 \%$ & $-15 \%$ & $-6 \%$ & $16 \%$ \\
\hline 23.32 & bricks, tiles and construction products, in baked clay & 360 & $-98 \%$ & $-51 \%$ & $-31 \%$ & $-11 \%$ & $610 \%$ \\
\hline 23.51 & cement & 198 & $-76 \%$ & $-22 \%$ & $-16 \%$ & $-10 \%$ & $49 \%$ \\
\hline 23.52 & lime and plaster & 184 & $-96 \%$ & $-39 \%$ & $-24 \%$ & $-10 \%$ & $82 \%$ \\
\hline 23.62 & plaster products for construction purposes & 7 & $-42 \%$ & $-36 \%$ & $-28 \%$ & $7 \%$ & $22 \%$ \\
\hline 24.1 & basic iron/steel; ferro-alloys & 226 & $-99 \%$ & $-35 \%$ & $-16 \%$ & $2 \%$ & $7621 \%$ \\
\hline 24.2 & tubes, pipes, hollow profiles and related fittings, of steel & 11 & $-94 \%$ & $-36 \%$ & $-22 \%$ & $-7 \%$ & $29 \%$ \\
\hline 24.51 & Casting of iron & 9 & $-90 \%$ & $-67 \%$ & $-42 \%$ & $-34 \%$ & $96 \%$ \\
\hline
\end{tabular}

The reductions do no spread uniformly across installations. For nearly two thirds of the installations, allocation in 2013 was between $50 \%$ and $100 \%$ of the allocation in 2008. However, roughly $15 \%$ of the installations in the sample experienced reductions in allocation of more than $50 \%$. For a quarter of installations the allocation increased, half of which had an increase of more than $25 \%$. Also within sectors, the installations were affected quite differently (Figure 2, Table 3). The median is negative for all sectors, and reductions are between $15 \%$ and $25 \%$ in most sectors. However, strong outliers exist. These are particularly pronounced in the paper sector (NACE Rev. 217.2) in which the 
allocation in 2013 exceeded the average allocation of the 2nd trading period by more than a factor of 2.5 for $10 \%$ of the installations (for 18 out of 493 installations the increases exceeded the factor 10). Still, the median change was a reduction of $-22 \%$. Also in the iron and steel sector (NACE Rev. 224.1) a number of installations had a strong increase in allocations 2013 compared to the average of the 2nd trading period: for $7.5 \%$ the increase was beyond a factor of 2.5 (for 5 out of 226 the increase exceeded the factor 10). But also in this case the median change is a reduction of $-16 \%$.
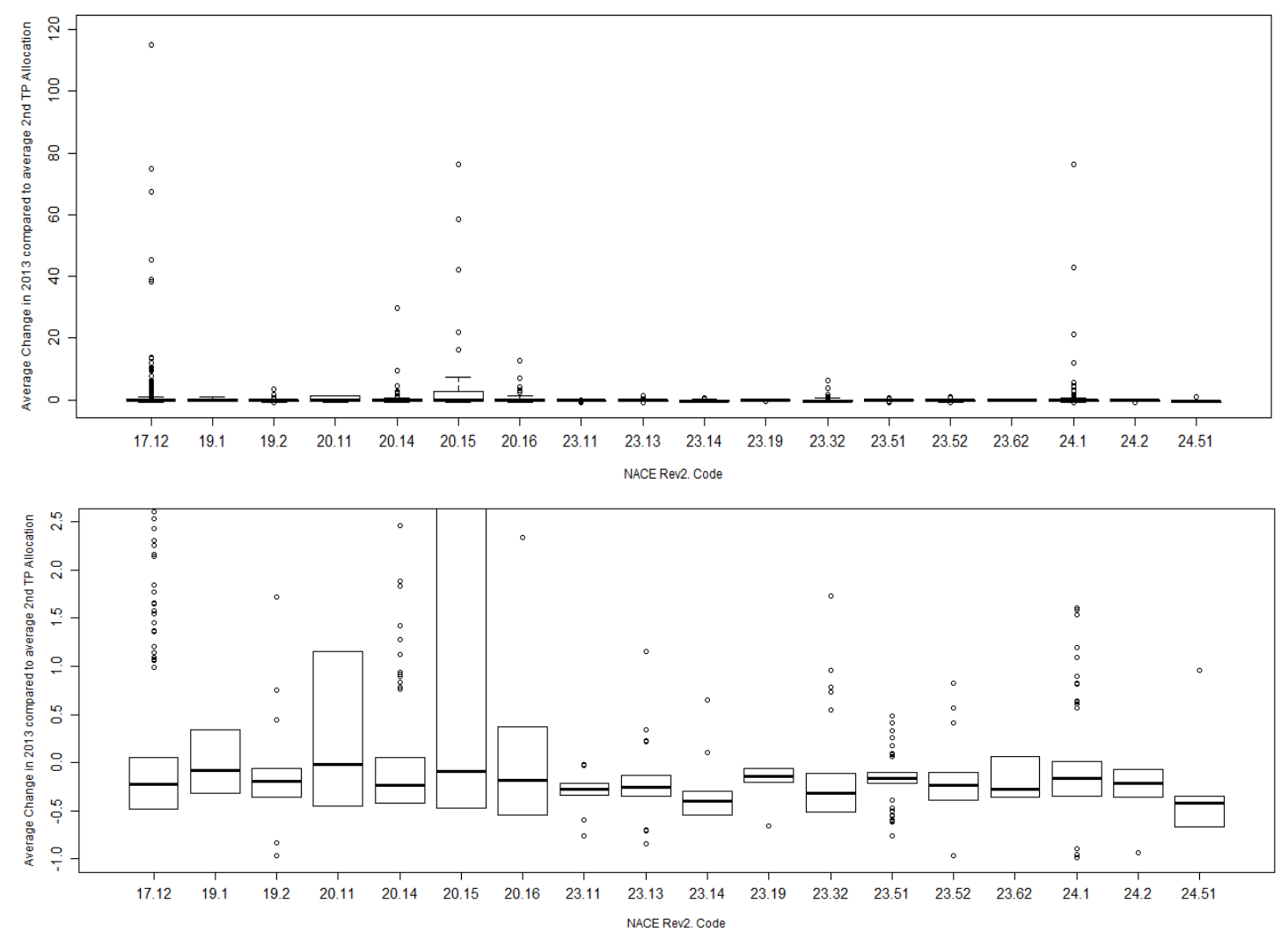

Figure 2. Spread of the Average Allocation Change in 2013 compared to the average of the 2nd Trading Period by NACE Code with different scaling of the vertical axis. Note: Top figure truncated at 120 which means three outliers from the paper sector are not displayed. Bottom figure truncated at 2.5. Dark lines indicate the median, the boxes mark the range containing 50\%, with half below the dark line and half above. The bars below and above indicate the 1st (lowest) and 4th quantiles. Dots indicate outliers that are defined as beyond $+/-1.5$ inter-quantile range from the ends of the thin bars.

\subsubsection{Allocation Changes at Country Level}

At country level, the strongest reduction took place in Latvia (-64\%), Romania ( $-45 \%)$ and the Slovak Republic (-34\%) (Figure 3). In all three countries allocation exceeded verified emissions in 2008 and does still do so in 2013 for Romania and Latvia. In four countries, Lithuania, Hungary, Austria and Norway aggregate allocation increased in 2013 compared to the average of the 2nd trading period.

In 2008, in 23 out of 27 countries allocation exceeded verified emissions. Even though allocations decreased in most countries, still in more than half of the countries, allocations exceed verified emissions in 2013. However, changes are quite disperse within the countries in particular driven by the heterogeneity of changes observed at sectoral level. 


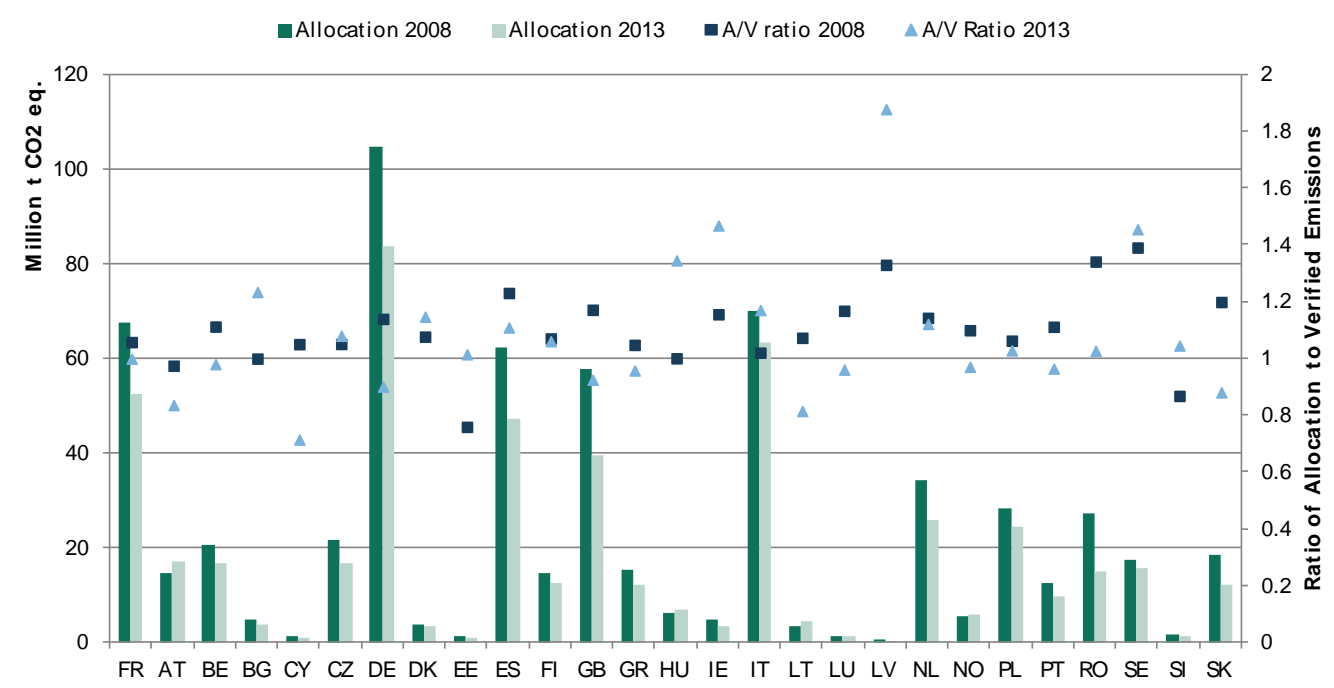

Figure 3. Allocations and Ratio of Allocations to Verified Emissions in 2008 and 2013 by Country.

\subsubsection{Allocation Changes and Verified Emissions for Country-Sector Pairs}

Looking at the heterogeneity of the allocation changes, the subsequent question is whether the changes contributed to reducing allocation surpluses that existed in 2008 and achieved a more harmonized allocation. Figure 4 displays a plot of the ratio of allocation to verified emissions in 2008-as an indicator for a historical allocation surplus or potential over-allocation-over the ratio of allocations 2013 to allocation for the average year of the 2nd trading period (dots based on median for country-sector pairs). This second ratio indicates whether with the new rules the historical allocation situation has been corrected.

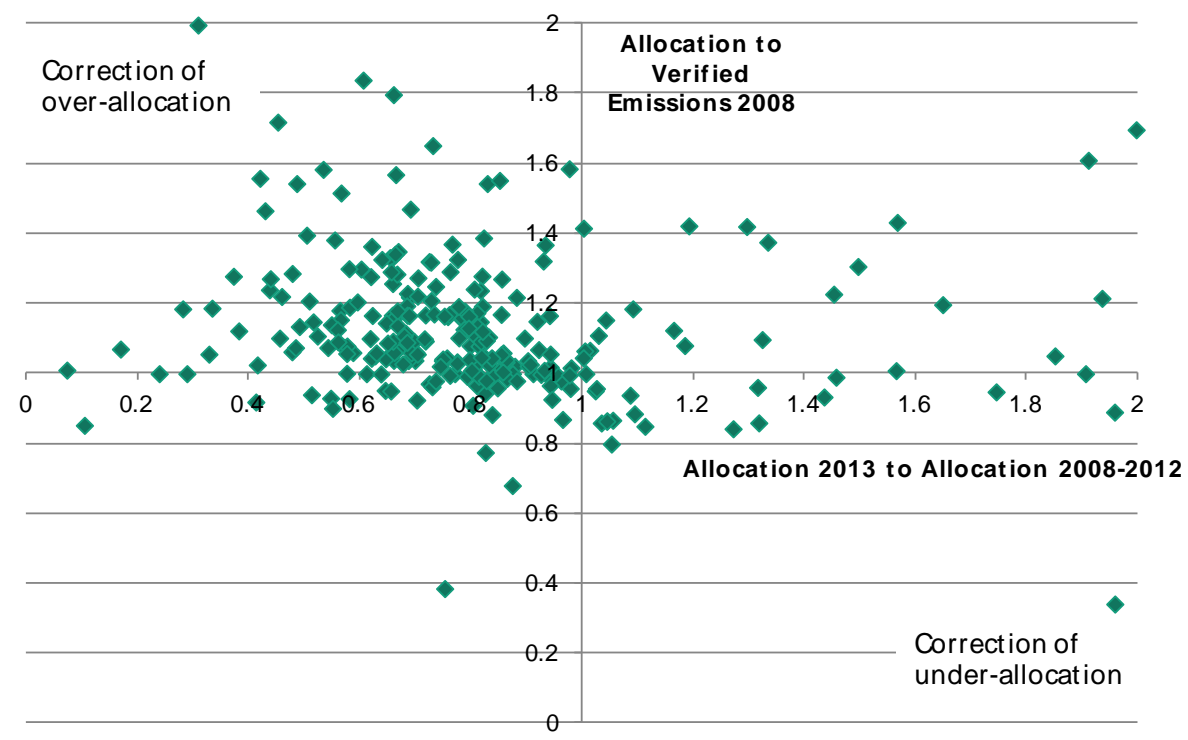

Figure 4. Scatterplot of Allocation to Verified Emissions Ratio 2008 over Ratio of Allocation 2013 to Average Allocation 2008-2012 (based on median values for country sector pairs). Each data point represents a country-sector pair. Note: $x$-axis truncated at 2 which hides 14 data points mostly from the chemical sector (17.12: EE. 20.11: CZ, SE, 20.15: FI, HU, LT, SK, GB, IT, PT, AT, 20.16: AT, HU, SE).

The scatter plot shows that for the majority of country sector pairs, the ratio of allocation 2013 to Average 2nd trading period was smaller than one while the ratio of allocations to verified emission in 2008 was larger than one (upper left quadrant in Figure 3). This can be interpreted as a correction of a 
potential historical over-allocation with the new allocation rules for the third trading period. A smaller number of country sector pairs appear in the bottom right quadrant which indicates a correction of under-allocation. There are also a couple of country sector pairs in the bottom left quadrant indicating that despite an allowance shortage in 2008, allocation further decreased in 2013 compared to the 2nd trading period. Furthermore, there are quite some country sector pairs for which allocation increased despite the ratio of allocations to verified emissions in 2008 being larger than 1 already. Most of these relate to the chemical sector 20.14, 20.15, 20.16 in which scope changes took place. However, there is also the Swedish paper sector at the very top right, coking installations in Spain and the Czech Republic. The same plots for within the paper sector (17.1), cement (23.51) and the iron and steel sector (24.1) look qualitatively the same. This indicates that the benchmark-based allocation contributed to harmonizing allocation by reducing allocation more strongly for installations which have been over-allocated in the past.

\subsection{Impact of Benchmarks for Allocation on Verified Emissions}

In this section we analyse in detail the evolution of specific emissions (per tonne of product) for the four products cement clinker, pig iron, ammonia and nitric acid. In analysis covers the period from 2005 to 2016/2017, as far as data are available.

\subsubsection{Cement}

Cement is a relatively homogenous product commonly used within construction. The production of cement involves a two-step process whereby clinker is firstly produced from heating raw materials (i.e., calcium, silicon, alumina and iron oxides) in a kiln at very high temperatures and secondly cement is then produced from clinker and other additives in a grinding mill. Producers of cement essentially compete on price alone due to the lack of product specialisation.

In our case study we present first the evolution of absolute $\mathrm{CO}_{2}$ emissions from cement clinker from three different sources (Figure 5):

- data from the EUTL data viewer [25] (activity 29, production of cement clinker);

- data from the GNR database run by the World Business Council for Sustainable Development WBCSD [26];

- data prepared for our case study based on the EUTL registers [19]. This concerned a selection of installations which had a continued production in the period 2005-2016 (i.e., plants which were only producing part of the period were taken out from the analysis. The dataset was corrected for the effect that the verified emissions also contain partly emissions from other sub-installations than cement clinker. This data set is rather close to the verified emissions of the selected data set as cement clinker sub-installations represent the overwhelming parts of the verified emissions of the installations. The correction was made based on the share of the clinker sub-installations in the period 2005-2010 (as obtained from NIMS data).

It can be observed that while emissions are decreasing over most of the time in all datasets (except for 2014), they are decreasing particularly strongly for the GNR dataset while the data set selected from the EUTL runs relatively parallel with the overall emissions as presented in the EUTL data viewer for the activity 29 (production of cement clinker) as a whole.

We identified the following main reasons for differences in the datasets through detailed discussions with Cembureau, the European cement association:

- Coverage of installations: We identified 241 installations in the EU EUTL as cement clinker plants. The emissions of the selection of installations are shown in Figure 5. This curve follows the trend in the EUTL data viewer rather parallel. The emissions from the 241 plants do not show the strong decrease in emissions as evident from the GNR data from 2011 onwards. It was emphasised by Cembureau that the coverage of cement installations in the GNR database fell from $98 \%$ of the 
total in 2011 to $95 \%$ in 2013, which contributes to the observed difference in verified emissions. However, it may possibly not impact much on specific emissions as a change in coverage would impact both on emissions and on production. If a production index is derived from the GNR database for clinker and used in combination with the emission data derived from the register, the specific emissions would increase in 2012-2013, given the change in coverage in production (derived from GNR) but not impacting also on the emissions (derived from the registers). Finally, several EUTL installations were removed by Cembureau on the grounds that the installations were not correctly classified under EUTL activity code and may in fact contain emissions from other processes (i.e., lime production).

- Changes in reporting protocol: Cembureau confirmed that part of the decline in emissions after 2012 in the GNR database is due to a change in accounting rules for emissions from waste. The change in methodology for emission factors has been operated actually to improve the comparability between the EUTL and GNR datasets as the GNR dataset was previously more stringent in accounting for waste emissions than the EUTL (according to the previous methodology, emissions from tire combustion were considered as originating from fossil fuels and taken fully into account by GNR. However about one quarter is biomass-based and considered as $\mathrm{CO}_{2}$-free in the new methodology). The change was introduced, starting in 2012. However, not all companies have been reporting immediately according to the new methodology. It is likely that 2012 and 2013 (perhaps also still 2014) is a mixture of reporting according to old and new methodology. It is clear that this change in accounting rules lowers the emissions starting 2012, as compared to the previous years.

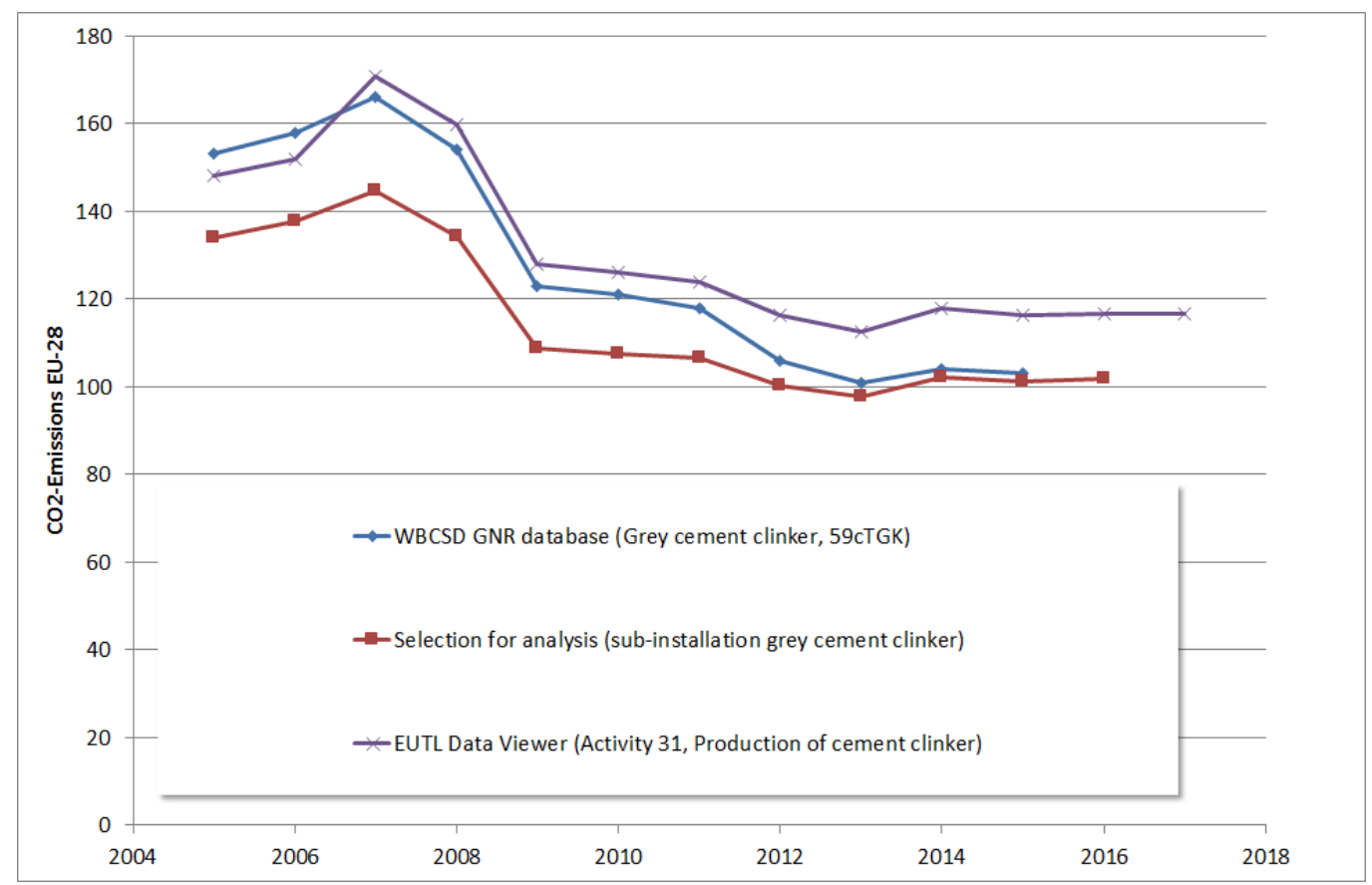

Figure 5. Overall greenhouse gas emissions of cement ( $\mathrm{Mt} \mathrm{CO}_{2}$-equ.) from three different sources. Source: Selection for analysis from EUTL [19]; own calculations, EUTL Data Viewer [25], WBCSD GNR database [26].

We further investigated two sources for the evolution of the production, in order to derive an index for the extension of our data set from 2005-2010, as explained in the methodological section:

- Prodcom production data [24] (code 23511100, production of cement clinker);

- the data from the GNR database run by the World Business Council for Sustainable Development WBCSD [26]. 
However, the Prodcom dataset only started in 2009 and the data seem incomplete, since for example in 2009 the production volume is about 30\% lower than the production provided by the association. We therefore used the production index derived from the WBCSD data, corrected, however, for the above mentioned fact that from 2011 to 2013 coverage of production dropped from $98 \%$ to $95 \%$. The index was then used to extrapolate the aggregate production data for our dataset, which was only available for the period 2005-2008 in exactly the same dataset as for $\mathrm{CO}_{2}$-emissions.

Figure 6 shows the evolution of the specific emissions (tonnes of $\mathrm{CO}_{2}$ eq. per tonne of product) for cement clinker. While the specific emissions provided by WBCSD show a somewhat decreasing trend, our own data set has on the contrary slightly increasing specific emissions. We explain this by the difference with the WBCSD GNR emissions, which from 2011 on are calculated with changed emission factors for biomass waste as compared to the period before 2011, while the emission factors in our dataset remain constant, as the emissions are taken from the EUTL. The slight increase in specific emissions according to our dataset could be the effect of a lower capacity use following the 2008/2009 economic crisis which made that cement clinker production in countries like Spain, Italy, Greece, Portugal etc. was considerably reduced in the years thereafter and is only slightly increasing over the period from 2014 onwards which leads to a slight curbing of the specific emissions due to a somewhat higher capacity factor.

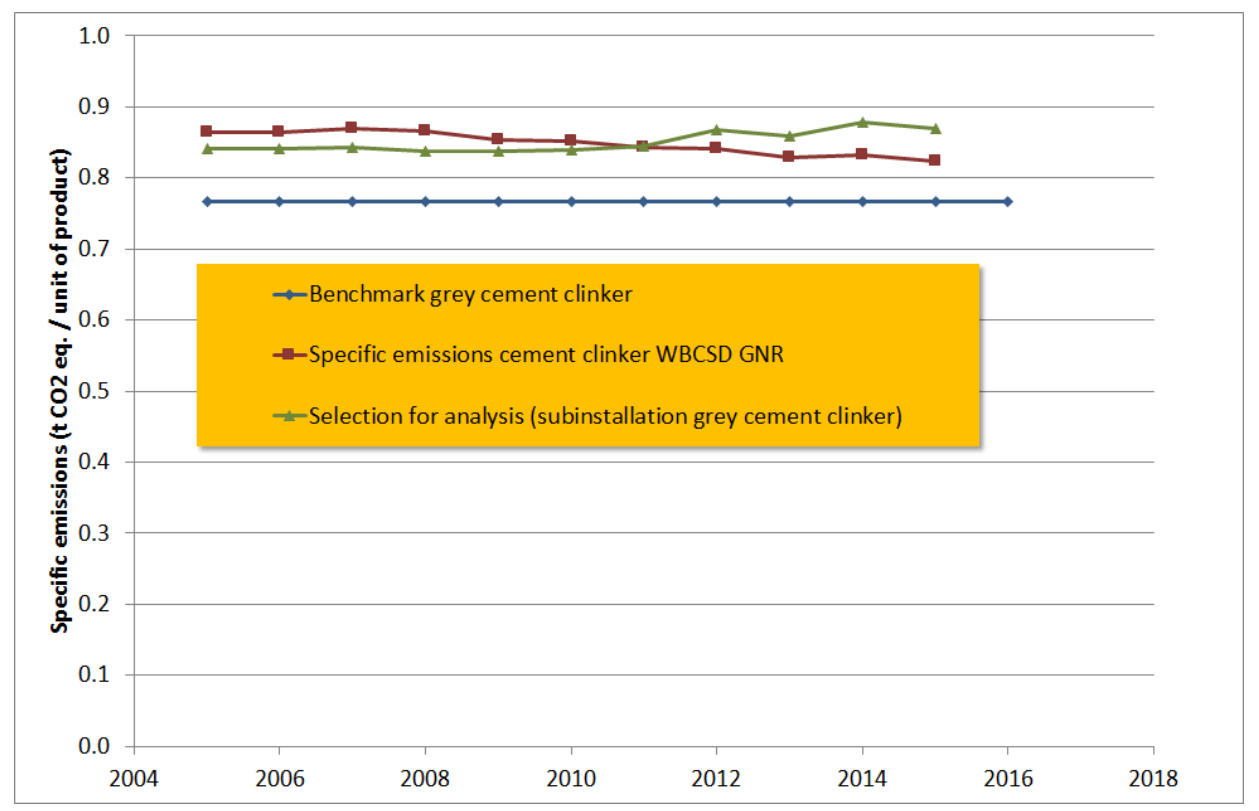

Figure 6. Specific emissions of cement clinker compared to the benchmark (straight line). Source: WBCSD database [26]; Benchmark for cement clinker [3]; own calculation [19].

Overall, the decreasing trend of specific emissions of the WBCSD database seems overstated due to the change in emission factor methodology while specific emissions have possibly remained stable, a picture which was blurred by less capacity use following the economic crisis, driving specific emission somewhat up. We observed that specific emissions have been fairly stable between 2005 and 2011 and were consistently above the benchmark value. Our results show an increase in specific emissions between 2011 and 2013, which imply that the benchmarking rules have so far not encouraged a decline in the specific emissions of cement clinker plants in Europe. It is possible that the specific emissions of several cement clinker plants may have increased due to lower rates of capacity utilisation and a temporary increase in the ratio of clinker used in cement due to declining domestic demand following the economic recession. Ultimately, through the availability of more up to date production data, collected independently for the selected dataset in installations, would allow for more robust findings in a future assessment. 


\subsubsection{Pig Iron Production (Molten Metal)}

Steel is an internationally traded commodity that is used as an intermediate product in many industries, in particular in the automotive and construction materials industries. Steel can be produced either via the more carbon intensive primary steel production route (blast furnace/basic oxygen furnace process- $\mathrm{BF} / \mathrm{BOF}$ ) primarily based on iron ore and coke or via the less emission intensive secondary EAF route primarily based on steel scrap and electricity.

The physical production used for the development of the benchmarks is the iron production. This was used as a proxy for molten metal which is used to calculate the benchmark according to Decision 2011/278/EU [3]. The assumption is that the ratio between molten metal and solid iron is fairly constant over time. Given the fact that we apply the index for 2009 to 2017 on a dataset of activities based on molten metal which covers the period 2005-2008, this should not influence the level of the specific emissions to a large degree.

We considered two sources for the production of iron:

- Prodcom production data [24] (code 2410T110, production of pig iron);

- $\quad$ The World Steel database [27]

For the iron processing industry the Prodcom data in physical indicators deviate quite considerably from the index derived from the World Steel dataset and the selected dataset of NIMS data set and seems less reliable. Therefore, it was decided to use an index for molten metal production derived from the World Steel database. Though there are differences in the absolute level between the two sources of about $18 \%$ in the period 2005-2008, the evolution of both indices is rather similar in this period. This index was therefore used to extrapolate the production data for the selected sample to 2017.

Figure 7 shows the $\mathrm{CO}_{2}$-emissions for iron production from two sources. First the data from the EU ETS data viewer [25] for the activities 24 pig iron and 25 production or processing of ferrous metals (we included the latter category in the analysis, as some of the EUTL data from the selected data set relate to this activity group) which contains all emission data, including for those installations which have not been producing constantly over the period 2005-2017. Second the selection of installations which have been constantly producing, either not corrected for the sub-installation share, or corrected for this share (which is roughly about $79 \%$ on average for the molten metal sub-installation).

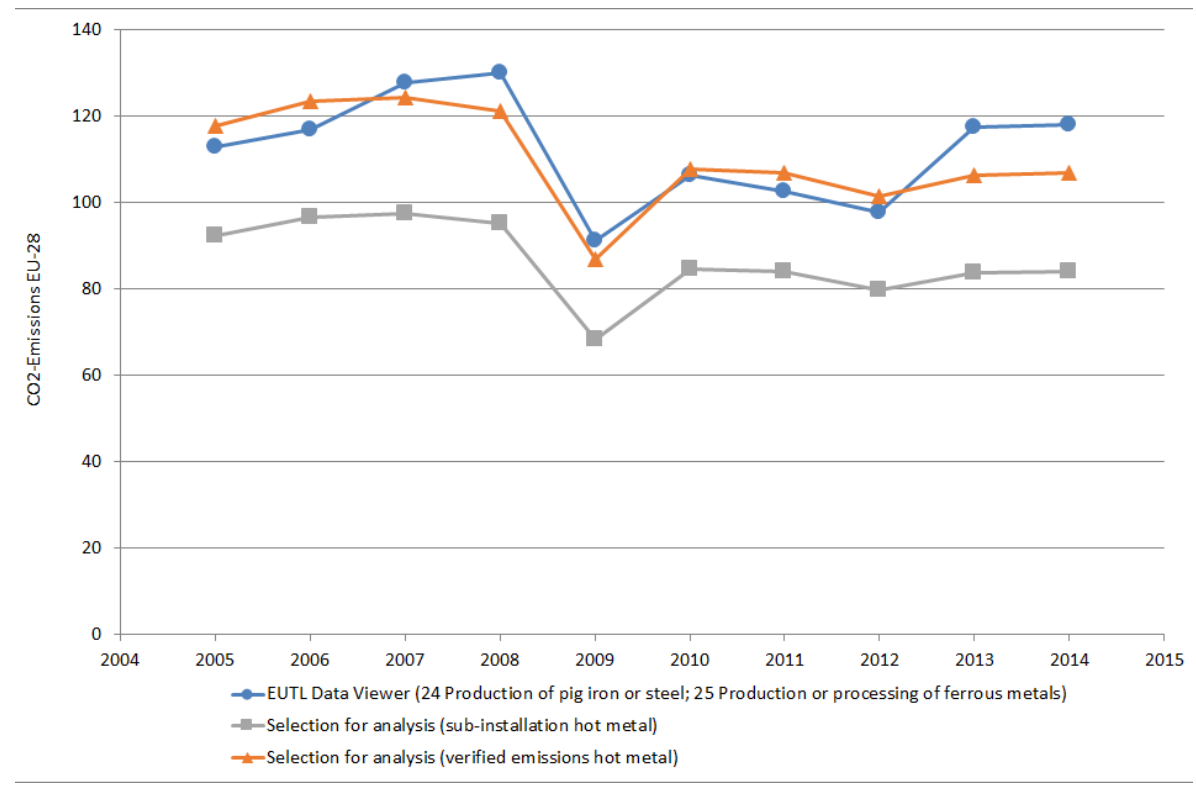

Figure 7. Overall greenhouse gas emissions ( $\mathrm{Mt} \mathrm{CO}_{2}$-equ.) of iron making from two different sources. Source: Selection for analysis from EUTL (verified emissions) and own calculations for the sub-installation molten metal [19], EUTL Data Viewer [25]. 
Figure 8 shows the resulting specific $\mathrm{CO}_{2}$-emissions for our selection from the EUTL data (without the correction for the share of the clinker sub-installation) compared to the emission benchmark of $1.328 \mathrm{t} \mathrm{CO}_{2}$ /tonne molten metal. Our data set shows a rather stable evolution of specific emissions over time, however with an increase in emissions around 2009 due to the effects of the economic crisis. After this period, the specific emissions decrease again but not totally to the pre-crisis level. However, the level of the specific emission close to the benchmark if the correction for the sub-installation share is not applied, or lower than the benchmark if the correction for the sub-installation for molten metal is applied, requires further discussion.

Following a discussion with the German Emission Trading Authority DEHST on German installations, we identified possible reasons for our specific emission calculation being below the hot metal benchmark value:

- Differences in the volume of molten metal and pig iron, which was used here, as a proxy: However, the differences are not important.

- A variety of installations are registered in an emission "bubble" which also includes other installations in an integrated steel mill. However, this would have as a result rather higher emissions compared to the benchmark.

- The most important point is, however, that waste gases arising from blast furnaces and steel converter are also exported to generate electricity, i.e., either within the integrated steel mill and hence possibly within the associated emission bubble. Or the export goes to another site. The issue is then how these emissions are accounted for between the provider of the waste gas and the electricity generators and how the associated allowances are distributed between user and provider of the waste gas. Though normally electricity generation is not receiving allowances for free, waste gases receive nevertheless allowances up to the level which makes them comparable with natural gas for electricity generation. For blast furnace gas, this is roughly three quarters of the emissions from that type of gas. If the allowances for this are largely given to the user, then the specific emissions of molten metal appear as lower than the benchmark. This arrives with a variety of installations.

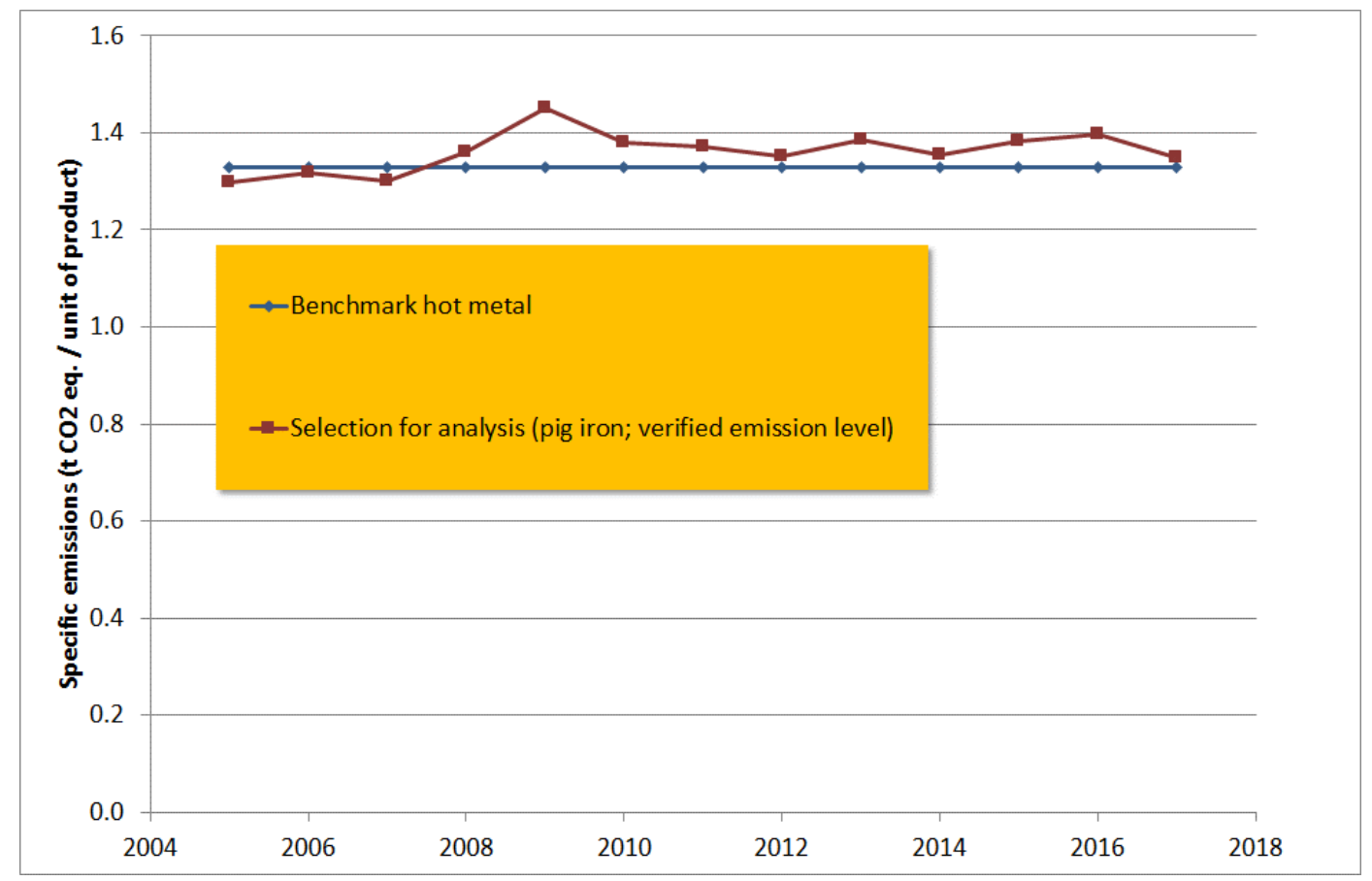

Figure 8. Specific emissions of pig iron compared to the benchmark for molten metal (straight line). Source: World Steel Association [27]; Benchmark for molten metal [3]; own calculation [19]. 
The interview with the German Emission Authority DEHST emphasizes the need for greater transparency with the accounting of the use of blast furnace gases in order to deliver more robust findings on the development of specific emissions within the iron and steel sector.

Nevertheless, while this issue influences the absolute level of specific emissions, the relative change is rather un-effected by this issue as long as the contractual arrangements for the repartition of allowances between producers and users of blast furnace gas remain similar over time. The relative change of the specific emissions over time is small, suggesting that-except for the period of the economic crisis in 2009, which has led to a rather low capacity use-there was no indication of low carbon technology being implemented to a substantial degree. Reference [28] analyses in detail the development of low-carbon technology in Germany steel industry and the barriers to its penetration. They come to a similar conclusion.

\subsubsection{Ammonia}

About $80 \%$ of the ammonia is currently used as the nitrogen source in fertilisers, with the other $20 \%$ being used in several industrial applications, such as the manufacture of plastics, fibres, explosives, hydrazine, amines, amides, nitriles and other organic nitrogen compounds which serve as intermediates in dyes and pharmaceuticals manufacturing. Among the important inorganic products manufactured from ammonia are nitric acid, urea and sodium cyanide. Ammonia is also used for environmental protection measures, e.g., in the removal of NOx from flue-gases. Liquid ammonia is an important solvent and is also used as a refrigerant. For the ammonia product group emissions are only available starting from 2013, as most of the emissions from this product group were only entered into the emission registers with Phase III of the EU ETS (Figure 9).

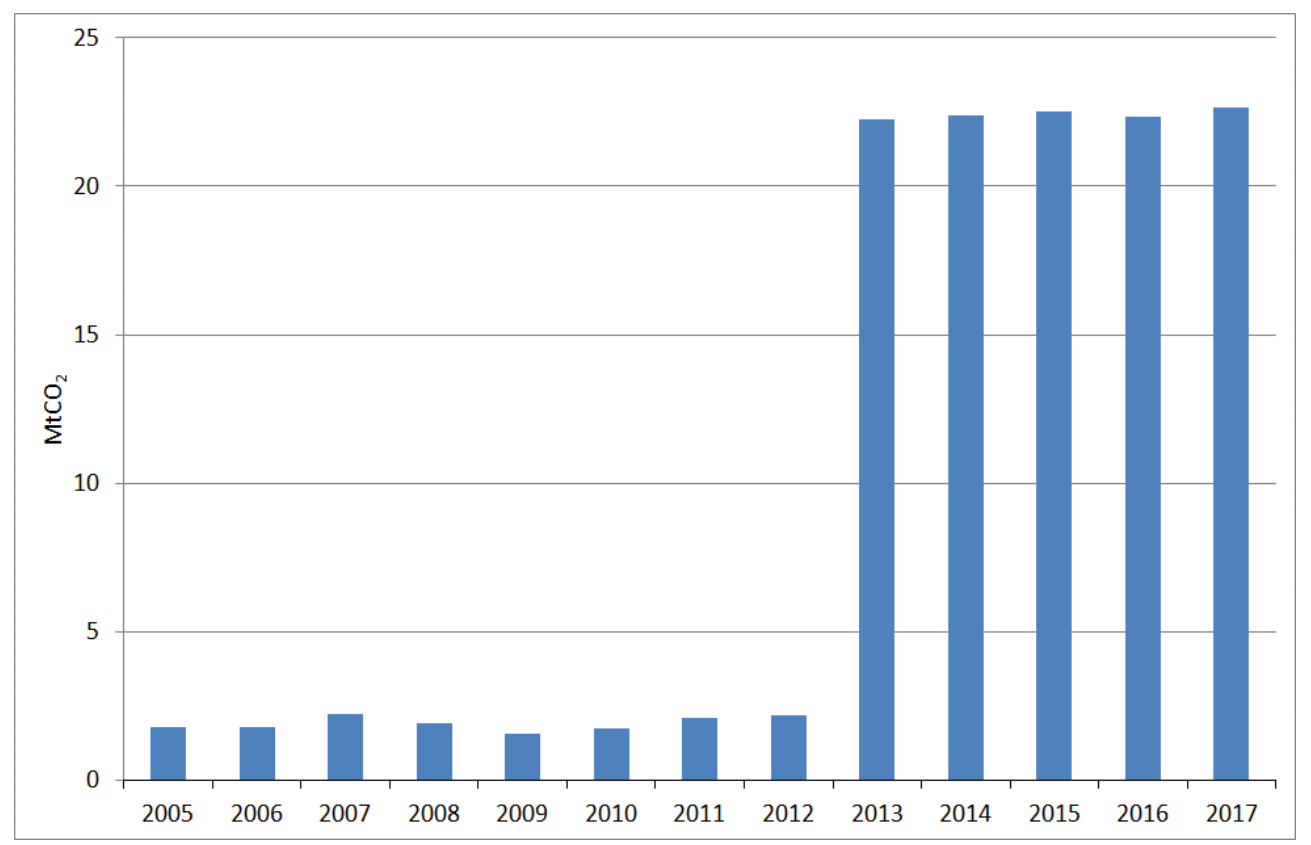

Figure 9. Overall greenhouse gas emissions of ammonia in the EU EUTL data. Source: Activity 41 (ammonia) [25].

Therefore the approach taken for example for cement or steel, as described above, could not be carried out due before 2013 due to the fact that only around $10 \%$ of the emissions are available for the period 2005-2012 which were already included into the EU ETS in Phase I and II. It was also not possible for ammonia to generate a totally harmonised approach between emissions and production, i.e., have exactly the same company set for both parameters, given the fact that ammonia was not included in the original data set for the period 2005-2010. In addition, the share of the 
main production process within the overall emissions of the installations could not be established with certitude. However, both factors should have more impact on the absolute level of the specific emissions rather than on the trends.

Figure 10 shows the evolution of the specific emissions (tonnes of $\mathrm{CO}_{2}$ eq. per tonne of product) for ammonia. It is seen that no clear trend can be derived for the specific consumption following 2013, if it would not be for a small increase after an initial drop.

We carried out an interview with the association representing the product, Fertilizers Europe. The following information on the historic evolution of specific energy consumption of ammonia before Phase III was provided by them [23]. This was based on regular surveys (every three years) being carried out on ammonia energy efficiency by Phillip Townsend Associates PTAI.

- The 2007-2008 average net energy efficiency of $35.2 \mathrm{GJ} / \mathrm{mt} \mathrm{NH3}$ was a $1.3 \%$ improvement over the previous period. This improvement is primarily a result of better efficiency performance by the same plants. Additional three new plants had a neutral impact on the average.

- The 2010-2011 average net energy efficiency of $34.9 \mathrm{GJ} / \mathrm{mt} \mathrm{NH3}$ was a $0.8 \%$ improvement over the previous period.

- The 2013-2014 average net energy efficiency of $34.8 \mathrm{GJ} / \mathrm{mt} \mathrm{NH3}$ was a $0.2 \%$ improvement over the previous period.

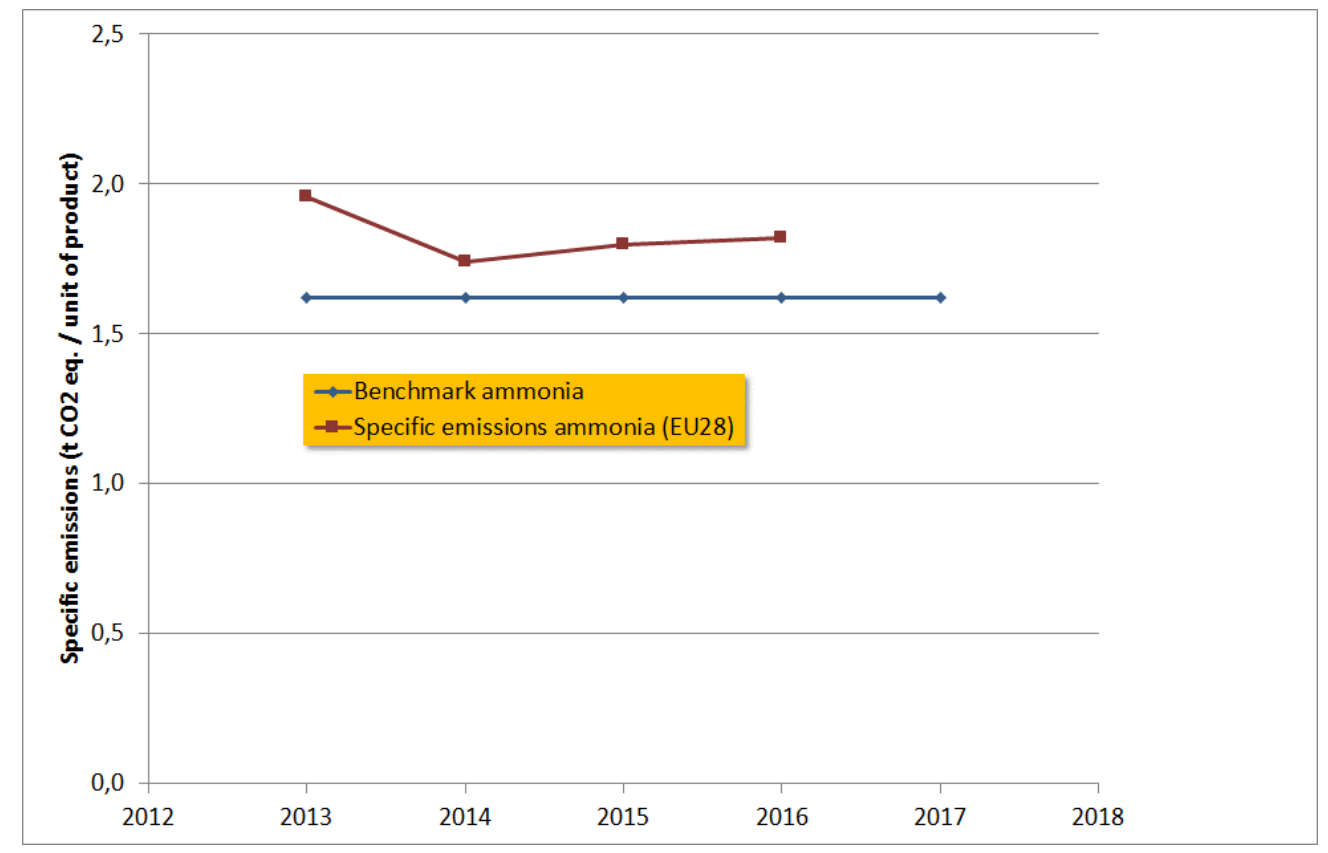

Figure 10. Specific emissions of ammonia compared to the benchmark (straight line). Source: Activity 41 (ammonia) [25]; Benchmark for ammonia [3]; Prodcom production data (code 20151075) [24].

In total, this shows that energy efficiency through the three surveys improved by around $2.3 \%$ in 9 years, or about $0.25 \%$ per year in the period 2004-2013. According to the sector association the improvements occurred mostly in Eastern Member States where the processes were still more inefficient. The driving force for this was, however, mainly increasing prices for natural gas, especially in Eastern Europe, who formerly profited from cheap natural gas from Russia (market driven improvement). The ETS would have had a minor role, especially as ammonia only entered the ETS formally in 2013. However, the perspective of the ETS could have spurred the uptake of new technology.

Nevertheless, the discussion with the association showed that fairly limited technical improvements happened within the plants in that time period, and combined with the analysis provided for the period 2013-2016, the impact of the benchmarks on ammonia appears as not visible. 


\subsubsection{Nitric Acid}

Nitric acid is also strongly related to fertilizers. Overall emissions for nitric acid are on the rise but this is due to the fact that not all emissions were included before 2013 (Figure 11). While the specific emissions of ammonia seemed to have been fairly stable over the years since 2005, according to Fertilizers Europe [23], the specific emissions of nitric acid have been decreasing by factor of 10 since 2005, due to the availability of the catalytic reduction technology (Figure 12). Already in 2009, when the benchmarks were established for nitric acid, the spread across the benchmarking curve was about 300 from best to worst, indicating the availability of a reduction technology which was already in the market. The question is raised about the role of the ETS in this change as this has been triggered before nitric acid entered the ETS in 2013. However, here also the discussion on the ETS and the benchmarks before 2013, which started around 2008, in fact, could have played an important role in the decision making processes of companies.

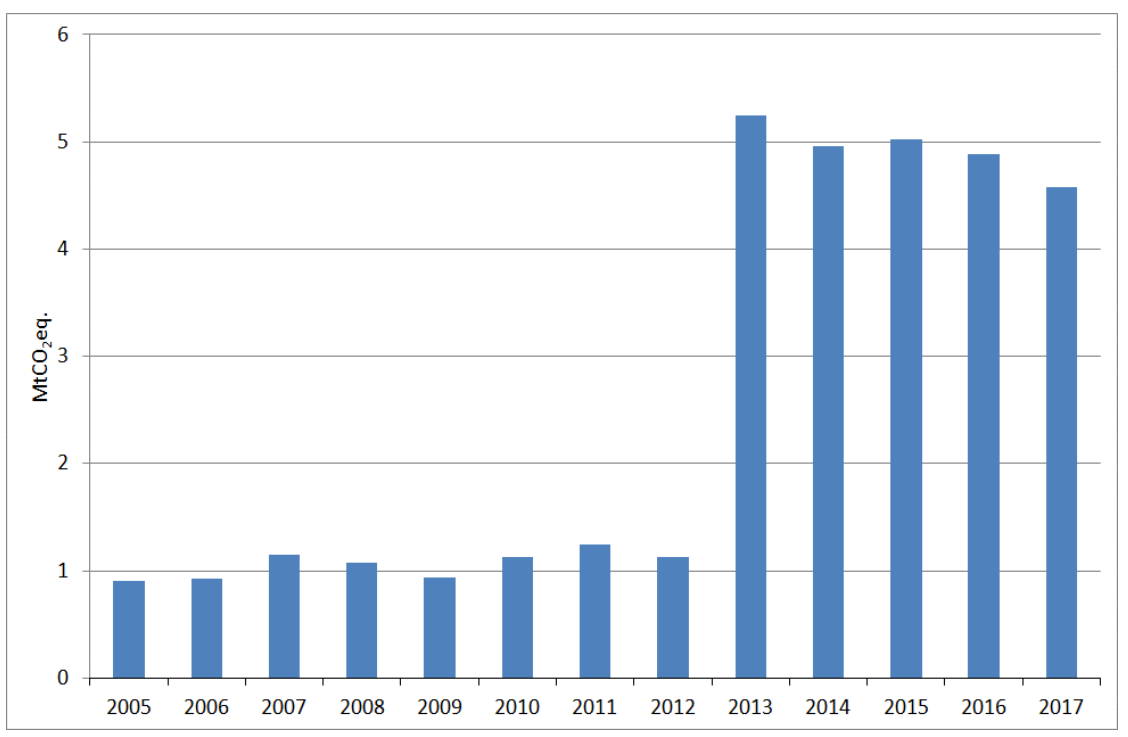

Figure 11. Overall greenhouse gas emissions of nitric acid in the EU EUTL data. Source: Activity 38 (nitric acid) [25].

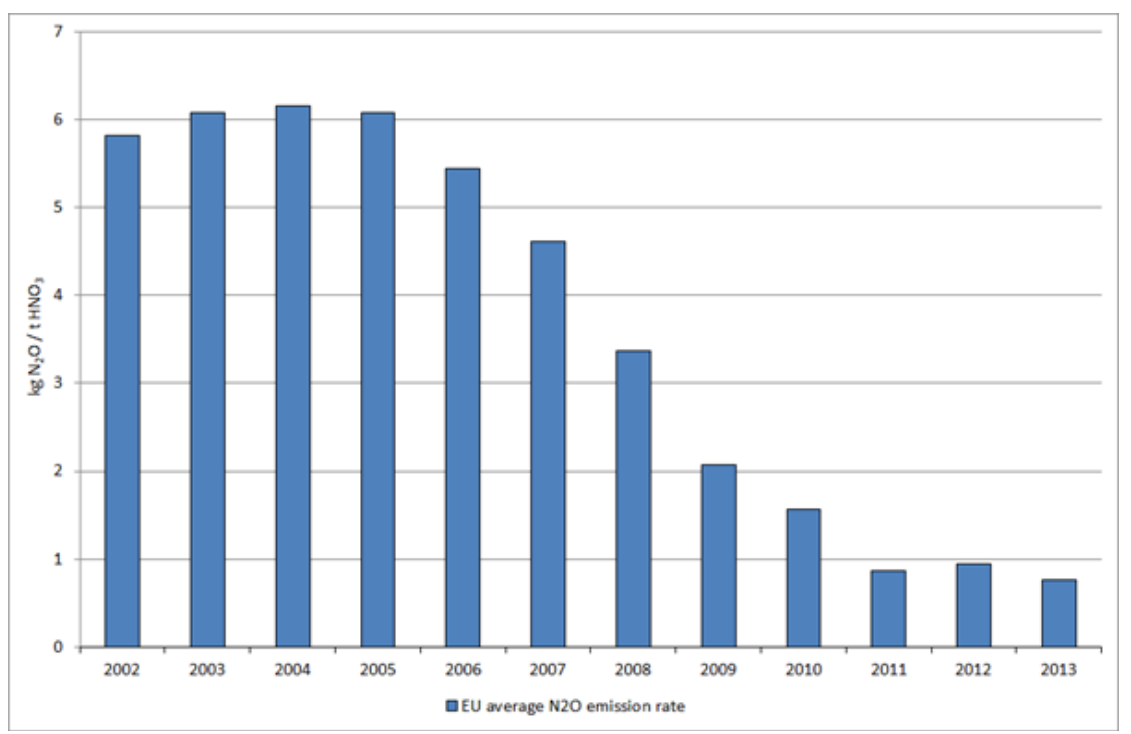

Figure 12. Specific emissions of nitric acid (EU average $\mathrm{N}_{2} \mathrm{O}$ emission rate). Source: [23]. 


\section{Discussion}

\subsection{Discussion of Results for the Comparison of Allocation with Actual Emissions}

The analysis indicates that even at the beginning of the second trading period, when the economic crisis had not yet had a strong effect on emissions, substantial surplus in allocation over verified emissions existed. Several other analyses came to similar results: For the first trading period [29] found high relative over-allocation in new member states, while at the contrary, under-allocation mostly occurred in Ireland, Italy, Spain, and the UK. The allocation based on historical emissions was criticized for not providing adequate incentives to increase emission efficiency. It was further vulnerable to strategically inflating emissions. Large inter-country difference in free allocation persisted in the $2 \mathrm{nd}$ trading period [2].

Reference [4] have substantiated the often formulated critique on the lacking harmonization of allocation based on decentralized national allocation plans for 1 st and 2 nd trading period. The question is then: did the move to benchmark-based allocation increase the harmonization of allocations across Europe?

According the results in answer of the first research question, the new allocation rules had a substantial effect on the allocation towards installations in the sample. Overall, allocation for the selected sectors decreased by $20 \%$ in 2013 compared to 2008 . The allocation change varies at sector level and by country:

- Allocation changes at sectoral: At the aggregate level, i.e., comparing the sum of allocations 2008-2013 per sector, allocation decreased in all but two sectors. On average the changed allocation contributed to the reduction of a surplus in allocations compared to verified emissions. While the ratio of allocation to verified emissions was larger than 1 in all but three sectors, the ratio was smaller than one in all but six sectors in 2013. For three sectors, in particular cement, the allocation to verified emissions ratio is larger in 2013 than in 2008 (see discussion below).

- Allocation changes at country level: In 2008, in 23 out of 27 countries allocation exceeded verified emissions. Even though allocations decreased in most countries, still in more than half of the countries, allocations exceed verified emissions in 2013. However, changes are quite disperse within the countries in particular driven by the heterogeneity of changes observed at sectoral level.

- Allocation changes and verified emissions for country-sector pairs: Looking at the heterogeneity of the allocation changes, the subsequent question is whether the changes contributed to reducing allocation surpluses that existed in 2008 and achieved a more harmonized allocation. The analysis of allocation/verified emission ratios for country-sector pairs shows that for the majority of country sector pairs, the ratio of Allocation 2013 to Average 2nd trading period was smaller than one while the ratio of allocations to verified emission in 2008 was larger than one. This can be interpreted as a correction of a potential historical over-allocation with the new allocation rules for the third trading period. The findings indicate that the benchmark-based allocation contributed to harmonizing allocation by reducing allocation more strongly for installations which have been over-allocated in the past.

Overall, with the move to Phase III the basis has been improved for the EU ETS to provide incentives to implement low carbon technology. Specific discussion items relate to specific products/issues:

- Cement: Previous analysis has found that for the cement sector installation emissions in 2012 clustered around capacity thresholds [30]. This indicates that installations' operators reduced production and strategically exploited the rules for capacity changes to optimize their allocation situation. This effect contributes to explaining that despite decreased allocation, the cement sector has a higher allocation surplus over verified emissions in 2013 than in 2008. Notably, this is likely not related to improvements in operational efficiency. On the contrary, operating several plants at reduced capacity instead of closing one and operating the other at full capacity leads to 
decreased efficiency. Furthermore, the ambition to retain certain clinker production levels to meet the threshold may have led to increase clinker ratios in cement production.

- Fertilisers and nitrogen compounds: The allocation increase in 2013 compared to 2008 at sector level for 20.15 Manufacture of fertilisers and nitrogen compounds (20.15) and 20.11 is driven by very high allocation changes in some installations. The median shows that most of the installations considered faced a decrease in allocation even though lower than in the other sectors. The installations with the largest allocation rise also had substantial changes in verified emissions from 2008 to 2013 which most likely relates to the changed scope of the EU ETS in its third trading period: Installations from the fertilizer sector only entered the EU ETS in 2013, but some installations have been liable to emissions trading before as thermal installations with a rated capacity of above $20 \mathrm{MW}$. Due to the low number of observations in the fertilizer sector particular effects from single installations have a stronger impact on the overall sector results.

- Pulp/paper: The treatment of cross-boundary heat flows probably strongly affected allocation in the paper sector in which combined heat and power installations are very common. For the paper sector in the Scandinavian countries numerous installations received an increased allocation in 2013 compared to the 2 nd trading period even though allocations exceeded verified emissions in 2008. There are two explanatory factors: (a) Scandinavian paper mills are often integrated mills using a high share of biomass inputs and waste from the pulping process. Those mills are better off compared to stand-alone paper production under benchmark based allocation; (b) under allocation based on historical emissions, these installations will have had relatively low allocations compared to mills using less biomass and/or stand-alone mill because they have fewer emissions.

\subsection{Discussion of Results for the Impacts of Benchmarks for Allocation on Verified Emissions}

In all of the four case studies, data issues are a challenge, notably for achieving s similar set of data, both for emission and production data. The EUTL only provides emission data. Hence, the comparison with the benchmarks is not straightforward, given that they are defined in terms of specific emissions (per tonne of product). A reduction in emissions per se may not be linked to an improvement in carbon efficiency but may be linked to changes in production, instead. Care had therefore to be taken to design an approach with a set of production data as close as possible to emission data. Further, plants not producing through the whole period falsify the picture as they may increase specific emissions due to low capacity use; those data had to be taken out from the analysis. Further, the benchmarks have been set in relation to sub-installations which are not identified in EUTL either and their shares had to be extracted from a previous data sets at the time when the benchmarks were established. Finally, economic recession such as in 2009 and the years onwards, has a strong impact on specific emissions due to low capacity use, and hence may drive specific emissions up. This discussion shows that such type of analysis would largely benefit, if the EUTL data would be complemented through suitable production information, at least in index form.

The results from the four product analyses can be summarized in Table 4 .

Table 4. Summary of results for the four case studies (cement clinker, pig iron, ammonia and nitric acid).

\begin{tabular}{ll}
\hline \multicolumn{1}{c}{ Product } & \multicolumn{1}{c}{ Observation } \\
\hline & $\begin{array}{l}\text { Specific emissions have been fairly stable between } 2005 \text { and } 2011 \text { and were consistently above the } \\
\text { benchmark value. Our results show an increase in specific emissions between 2011 and 2013, } \\
\text { which imply that the benchmarking rules have so far not encouraged a decline in the specific } \\
\text { emissions of cement clinker plants in Europe. It is possible that the specific emissions of several } \\
\text { cement clinker plants may have increased due to lower rates of capacity utilisation and a } \\
\text { temporary increase in the ratio of clinker used in cement due to declining domestic demand } \\
\text { following the economic recession. }\end{array}$ \\
\hline
\end{tabular}


Table 4. Cont.

\begin{tabular}{|c|c|}
\hline Product & Observation \\
\hline Pig iron & $\begin{array}{l}\text { The relative change of the specific emissions over time is small, suggesting-except for the period } \\
\text { of the economic crisis in 2009, which has led to a rather low capacity use-no indication of low } \\
\text { carbon technology being implemented to a substantial degree. Our specific emission calculation } \\
\text { provide an absolute level below the hot metal benchmark: the reason is that emissions and } \\
\text { allowances can be shared among producers and users of blast furnace gases for electricity } \\
\text { generation. Though normally electricity generation is not receiving allowances for free, waste } \\
\text { gases receive nevertheless allowances up to the level which makes them comparable with natural } \\
\text { gas for electricity generation (For blast furnace gas roughly three quarters of the emissions). If the } \\
\text { allowances for this are largely given to the user, then the specific emissions of molten metal appear } \\
\text { as lower than the benchmark. This arrives with a variety of installations. }\end{array}$ \\
\hline Ammonia & $\begin{array}{l}\text { Energy efficiency improved through three surveys carried out by Fertilizer Europe by around } 2.3 \% \\
\text { in } 9 \text { years, or about } 0.25 \% \text { per year in the period 2004-2013 (mostly in Eastern Member States } \\
\text { where the processes were still more inefficient and the change brought economic benefits given } \\
\text { increasing prices for natural gas) The ETS would have had a minor role, especially as ammonia } \\
\text { only entered the ETS formally in 2013. However, the perspective of the ETS could have spurred } \\
\text { the uptake of new technology. The analysis provided for the period 2013-2016 shows a rather flat } \\
\text { evolution of specific emissions from ammonia appears. }\end{array}$ \\
\hline Nitric acid & $\begin{array}{l}\text { Overall emissions for nitric acid are on the rise but this is due to the fact that not all emissions } \\
\text { were included before } 2013 \text { The specific emissions of nitric acid have been decreasing by factor of } \\
10 \text { since 2005, due to the availability of the catalytic reduction technology. Already in 2009, } \\
\text { when the benchmarks were established for nitric acid, the spread across the benchmarking curve } \\
\text { was about } 300 \text { from best to worst, indicating the availability of a reduction technology which was } \\
\text { already in the market. The question is raised about the role of the ETS in this change as this has } \\
\text { been triggered before nitric acid entered the ETS in 2013. However, here also the discussion on the } \\
\text { ETS and the benchmarks before } 2013 \text { could have played an important role in the decision making } \\
\text { processes of companies. }\end{array}$ \\
\hline
\end{tabular}

\section{Conclusions and Outlook}

Our analysis shows the allocation process for Phase III has largely improved the incentives for low-carbon technology uptake by reducing over-allocation though for a number of country-sector pairs some over-allocation remains. On the other hand, the evidence from the four case studies (cement clinker, pig iron, ammonia and nitric acid), which together represent around $40 \%$ of industrial emissions under the EU ETS, indicates that there was little impact so far, from the EU ETS on the evolution of specific carbon emissions, hence no substantial uptake of low-carbon technology in those production processes. Exception is the nitric acid process where, however, most of the change occurred before 2013. This change has, nevertheless, certainly benefitted from the introduction and discussion of the benchmarks around the period 2008/2009, anticipating the introduction of the benchmarks in 2013. The industrial process has benefitted from the fact that an important GHG reduction technology was available and could be taken up by a large number of companies in the ETS in a reasonable time frame.

This raises the question of how such alternatives can be developed for other sectors such as cement clinker, iron steel and other large emitters under the EU ETS. Such processes are in different stages of development as evidenced by the discussion around the Innovation Fund [14] to be set up for Phase IV of the EU ETS, i.e., starting 2020. The rising carbon prices-in recent weeks around 16 Euro/tonne $\mathrm{CO}_{2}$ was reached, after seven years of low prices at 5-6 Euro/tonne $\mathrm{CO}_{2}$-will reinvigorate companies' interest in bringing forward innovative low-carbon production processes. The over-supply in Phase III will rapidly disappear in Phase IV, in particular also through the reserve features developed for the period after 2020. This will increase pressure on politics to exempt carbon-intensive productions by increasing free allocation with the competitiveness and carbon leakage argument. However, with the now operating ETS in South Korea (start in 2015; price levels at 17,18 Euro/tonne $\mathrm{CO}_{2}$ ) and China (the national scheme has started in 2018), this debate gets more subtle and the pressure increases to develop for competitiveness reasons the first low-carbon processes for the production of crude steel, cement etc. Otherwise, increasingly also substitution by other, less carbon-intensive, materials, less subject to carbon price, will occur over time. 
Author Contributions: W.E. carried out the analysis for research question 2 (impact of benchmarks on verified emissions. He wrote the overall paper and the sections related to research question 2. N.F. carried out the analysis for research question 1 and wrote the parts of the paper related to this analysis (change in the ratios of allocation/verified emissions between Phase II and Phase III). S.H. and K.S. contributed to the analysis of the cement industry under research question 2.

Acknowledgments: The authors wish to thank the interview partners who have contributed with their knowledge, notably Cembureau, Fertilizers Europe and the German Emission Trading Authority DEHST. No funds for covering the costs to publish in open access have been received.

Conflicts of Interest: The authors declare no conflict of interest.

\section{References}

1. Del Río González, P. Harmonization versus decentralization in the EU ETS: An economic analysis. Clim. Policy 2006, 6, 457-475. [CrossRef]

2. Betz, R.; Rogge, K.; Schleich, J. EU emissions trading: An early analysis of national allocation plans for 2008-2012. Clim. Policy 2006, 6, 361-394. [CrossRef]

3. European Commission. Commission Decision of 27 April 2011 determining transitional Union-wide rules for harmonised free allocation of emission allowances pursuant to Article 10a of Directive 2003/87/EC of the European Parliament and of the Council. Off. J. Eur. Union 2011, L130, 1-45.

4. Sartor, O.; Pallière, C.; Lecourt, S. Benchmark-based allocations in EU ETS Phase 3: An early assessment. Clim. Policy 2014, 14, 507-524. [CrossRef]

5. Ellerman, A.D.; Convery, F.J.; de Perthuis, C. Pricing Carbon: The European Union Emissions Trading Scheme; Cambridge University Press: Cambridge, UK, 2010; ISBN 978-05-21-19647-5.

6. Ellermann, A.D.; Mercantonini, A.; Zaklan, A. The European Union Emissions Trading System: Ten Years and Counting. Rev. Environ. Econ. Policy 2010, 10, 89-107. [CrossRef]

7. Muûls, M.; Colmer, J.; Martin, R.; Wagner, U.J. Evaluating the EU Emissions Trading System: Take It or Leave It? An Assessment of the Data after Ten Years. Grantham Institute Briefing Paper No. 21. Imperial College London. October 2016. Available online: https:/ / www.imperial.ac.uk/media/imperial-college/ grantham-institute/public/publications/briefing-papers/Evaluating-the-EU-emissions-trading-system_ Grantham-BP-21_web.pdf (accessed on 31 May 2018).

8. Fallmann, H.; Heller, C.; Seuss, K.; Voogt, M.; Phylipsen, D.; van Iersel, S.; Oudenes, M.; Zelljadt, E.; Tröltzsch, J.; Duwe, M.; et al. Evaluation of the EU ETS Directive; Publications Office of the European Union: Luxembourg, 2016; ISBN 978-92-79-55340-0. Available online: https:/ / publications.europa.eu/en/publication-detail/- / publication/0478baf0-d6d4-11e5-8fea-01aa75ed71a1/language-en (accessed on 31 May 2018).

9. Sato, L.; Laing, T.; Cooper, S.; Wang, L. Methods for Evaluating the Performance of Emissions Trading Schemes. Climate Strategies Discussion Paper. November 2015. Available online: https:/ climatestrategies. org/wp-content/uploads/2015/11/CS-ChinaETS-Evaluation-paper-final1.pdf (accessed on 31 May 2018).

10. Umweltbundesamt. Evaluierung und Weiterentwicklung des EU-Emissionshandels. Climate Change 16/2016. Umweltbundesamt: Berlin, Germany. Available online: https://www.umweltbundesamt. de/sites/default/files/medien/378/publikationen/climate_change_16_2016_evaluierung_und_ weiterentwicklung_des_eu-emissionshandels.pdf (accessed on 31 May 2018). (In German)

11. Healy, S.; Schumacher, K.; Eichhammer, W. Analysis of Carbon Leakage under Phase III of the EU Emissions Trading System: Trading Patterns in the Cement and Aluminium Sectors. Energies 2018, 11, 1231. [CrossRef]

12. Nils, A.; Oberndorfer, U. Firm Performance and Employment in the EU Emissions Trading Scheme: An Empirical Assessment for Germany. Energy Policy 2008, 36, 12-22. [CrossRef]

13. Rogge, K. Reviewing the Evidence on the Innovation Impact of the EU Emission Trading System. SSRN Electron. J. 2016. [CrossRef]

14. Finance for Innovation: Towards the ETS Innovation Fund. Available online: https:/ / ec.europa.eu/clima/ events/articles/0115_en (accessed on 2 May 2018).

15. Betz, R.A.; Schmidt, T.S. Transfer patterns in Phase I of the EU Emissions Trading System: A first reality check based on cluster analysis. Clim. Policy 2015, 16, 474-495. [CrossRef]

16. Duscha, V.; del Rio, P. An economic analysis of the interactions between renewable support and other climate and energy policies. Energy Environ. 2016, 28, 11-33. [CrossRef] 
17. Schlomann, B.; Eichhammer, W. Interaction between Climate, Emissions Trading and Energy Efficiency Targets. Energy Environ. 2014, 25, 709-731. [CrossRef]

18. Heindl, P. The impact of administrative transaction costs in the EU emissions trading system. Clim. Policy 2015, 17, 314-329. [CrossRef]

19. European Union Transaction Log (EUTL). Available online: http://ec.europa.eu/environment/ets/welcome. do (accessed on 2 May 2018).

20. NACE Rev. 2-Statistical Classification of Economic Activities. Available online: http://ec.europa.eu/ eurostat/web / products-manuals-and-guidelines /- /KS-RA-07-015 (accessed on 2 May 2018).

21. European Commission. Commission Decision of 27 October 2014 determining, pursuant to Directive 2003/87/EC of the European Parliament and of the Council, a list of sectors and subsectors which are deemed to be exposed to a significant risk of carbon leakage, for the period 2015 to 2019. Off. J. Eur. Union 2014, L308/114, 114-124.

22. Reuter, M.; Eichhammer, W. Applying ex-post index decomposition analysis to final energy consumption for evaluating European energy efficiency policies and targets. Energy Effic. 2018, under review.

23. Fertilizers Europe; Auderghem, Belgium. Phillip Townsend Associates PTAI on behalf of Fertilizer Europe. Personal communication, 2016.

24. Prodcom-Statistics by Product. Excel Files (NACE Rev.2), Various Years. Available online: http:/ / ec.europa. eu/eurostat/web/prodcom/data/excel-files-nace-rev.2 (accessed on 2 May 2018).

25. EU Emissions Trading System (ETS) Data Viewer. Available online: https://www.eea.europa.eu/data-andmaps / dashboards / emissions-trading-viewer-1 (accessed on 2 May 2018).

26. Global Cement Database on $\mathrm{CO}_{2}$ and Energy Information. "Getting the Numbers Right" (GNR) Atabase. World Business Council for Sustainable Development WBCSD. Available online: http:/ www.wbcsdcement. org/index.php/key-issues/climate-protection/gnr-database (accessed on 2 May 2018).

27. World Steel Association. Steel Statistical Yearbook 2017. Available online: https://www.worldsteel.org/en/ dam/jcr:3e275c73-6f11-4e7f-a5d8-23d9bc5c508f/Steel+Statistical+Yearbook+2017.pdfandpreviousyears (accessed on 2 May 2018).

28. Arens, M.; Worrell, E.; Eichhammer, W. Drivers and barriers to the diffusion of energy-efficient technologiesA plant-level analysis of the German steel industry. Energy Effic. 2017, 2, 441-457. [CrossRef]

29. Anderson, B.; Di Maria, C. Abatement and Allocation in the Pilot Phase of the EU ETS. Environ. Resour. Econ. 2011, 48, 83-103. [CrossRef]

30. Climate Strategies. Carbon Control and Competitiveness Post 2020: The Cement Report. Final Report. February 2014. Available online: http://climatestrategies.org/wp-content/uploads/2014/02/climatestrategies-cement-report-final.pdf (accessed on 2 May 2018). 